\title{
PENGARUH KECEPATAN PENGELASAN MIG PADA PIPA SC-80 TERHADAP STRUKTUR MIKRO DAN KEKERASAN DENGAN POSISI PENGELASAN 1G
}

\author{
${ }^{1}$ Rishi Nur Maret, ${ }^{1}$ Syaripuddin, dan ${ }^{2}$ Ferry Budhi Susetyo \\ ${ }^{1}$ Program Studi Pendidikan Teknik Mesin, Fakultas Teknik, Universitas Negeri Jakarta \\ ${ }^{2}$ Program Studi Teknik Mesin, Fakultas Teknik, Universitas Negeri Jakarta \\ E-mail: fbudhi@unj.ac.id
}

\begin{abstract}
Abstrak
Dilakukan penelitian dengan variasi kecepatan pengelasan menggunakan alat bantu pengelasan untuk memutar spesimen. Variasi kecepatan putar alat bantu pengelasan 1, 1,5 dan 2 rpm. Penelitian ini bertujuan untuk mengetahui karakteristik hasil pengelasan pipa SC-80 pada las MIG dengan variasi putaran alat bantu. Posisi pengelasan yang digunakan $1 G$, dengan arus yang diatur tetap 100A, kecepatan wire feeder yang digunakan 4m/menit dan kawat las ER 70S-6 berdiameter 0,8 mm. Spesimen hasil pengelasan di lakukan uji kekerasan dan pengamatan struktur mikro. Spesimen yang memiliki nilai kekerasan tertinggi adalah spesimen dengan kecepatan putar alat bantu pengelasan 2 rpm. Dengan nilai kekerasan daerah HAZ sebesar 161,33 HV, dan Weld Metal 164,33 HV. Spesimen yang memiliki nilai kekerasan terendah adalah spesimen dengan kecepatan putar alat bantu pengelasan pipa 1 rpm. Dengan kekerasan daerah HAZ sebesar 148,67 HV, dan Weld Metal sebesar 146,33 HV.
\end{abstract}

Kata kunci: SC-80, MIG, Kekerasan, Struktur Mikro

\begin{abstract}
Conducted research with welding speed variations using welding aids to rotate the specimen. Variation of the rotating speed of welding aids $1,1.5$ and $2 \mathrm{rpm}$. This study aims to determine the characteristics of the SC-80 pipe welding results in MIG welding with a variety of tool rotation. The welding position used is $1 G$, with the current set to 100A, the wire feeder speed used is $4 \mathrm{~m} / \mathrm{min}$ and the ER 70S-6 welding wire is $0.8 \mathrm{~mm}$ in diameter. Welding specimens are tested hardness and microstructure observation. Specimens that have the highest hardness value are specimens with a rotating speed of welding aids of $2 \mathrm{rpm}$. With a HAZ area hardness value of $161.33 \mathrm{HV}$, and Weld Metal 164.33 HV. Specimens that have the lowest hardness value are specimens with a rotating speed of $1 \mathrm{rpm}$ pipe welding aids. With HAZ area hardness of $148.67 \mathrm{HV}$, and Weld Metal of 146.33 $H V$.
\end{abstract}

Keywords: SC-80, MIG, hardness, microstructure

\section{PENDAHULUAN}

Pengelasan MIG merupakan proses penyambungan dua material logam atau lebih menjadi satu melalui proses pencairan setempat(Harsono dkk, 2000). Elektroda yang digunakan adalah elektroda gulungan (filler metal) yang memiliki karakteristik yang sama dengan logam dasarnya (base metal). Pada saat proses pengelasan dialirkan gas pelindung agar tidak terjadi inklusi oksigen pada saat pencairan logam (Amstead dkk, 1997).

Hasil pengelasan dipengaruhi oleh laju aliran gas, besar arus, polaritas dan kecepatan pengelasan. Semakin tinggi laju aliran gas maka akan semakin tinggi kekuatan tarik, kekuatan luluh dan kekerasannya (Junus, 2011) (Prasetya, dkk 2017). Selain itu semakin tinggi laju aliran gas maka akan semakin baik penetrasinya (Harsono dkk, 2000). Pada pengelasan Al seri 1000 pada variasi arus 165 sd 210A semakin tinggi kuat arus maka akan semakin tinggi kekutan tariknya hingga arus 180A, namun pada arus 195 dan 210A kekuatan tarik semakin menurun (Muku dkk, 2009).

Untuk itu akan dilakukan penelitian dengan melakukan variasi kecepatan pengelasan dengan menggunakan alat bantu pengelasan untuk memutar spesimen. 


\section{METODOLOGI}

Pada penelitian ini spesimen menggunakan pipa baja SC-80 jenis seamless, yaitu baja karbon rendah tanpa sambungan las. Proses pengelasan di laboratorium Las Teknik mesin UNJ menggunakan alat bantu dan mesin las MIG SAF Junior 283 menngunakan elektroda ER70S6 dengan diameter $0,8 \mathrm{~mm}$. Proses pengelasan menggunakan polaritas DCRP dan arus $100 \mathrm{~A}$. Alat bantu pengelasan di atur dengan variasi 1, 1,5 dan $2 \mathrm{rpm}$. Ukuran spesimen dapat dilihat pada gambar 1. Setelah selesai pembuatan spesimen kemudian dilakukan pengamatan foto mikro serta pengujian keras di BPPT Puspitek Serpong. Pengujian keras menggunakan alat frank finotest dengan metode hardness vickers (hv), beban $5 \mathrm{kgf}$, waktu 15 detik temperatur $28^{\circ} \mathrm{C}$, sudut identor $136^{\circ}$ dan kondisi permukaan polishing/etching.

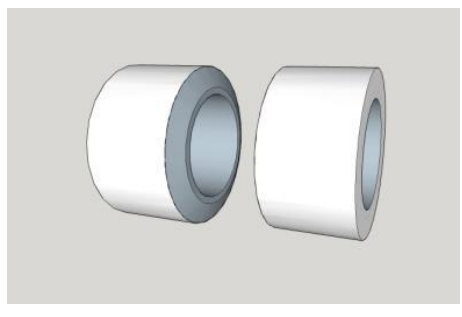

(a)

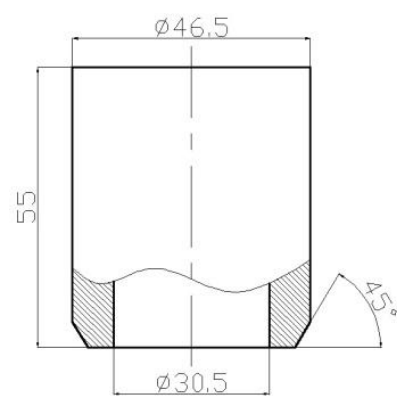

(b)

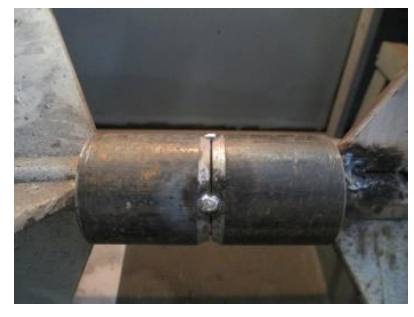

(c)

Gambar 1. (a) 3D Spesimen, (b) Ukuran Spesimen (mm) dan (c) Tack weld

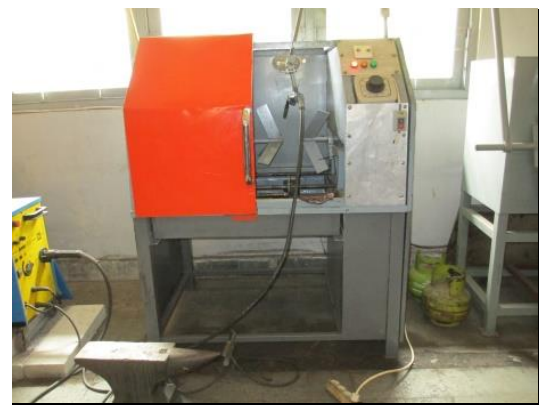

(a)

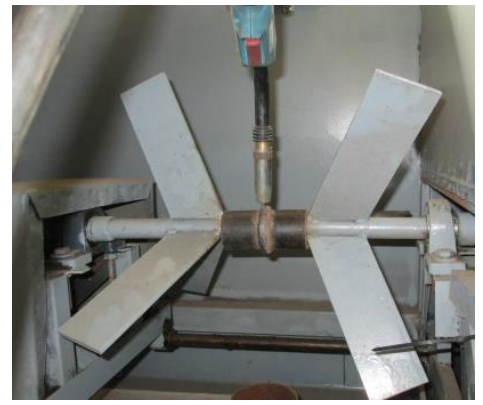

(b)

Gambar 2. Pembuatan Spesimen (a) Mesin Las MIG dan Alat Bantu, (b) Proses Pengelasan

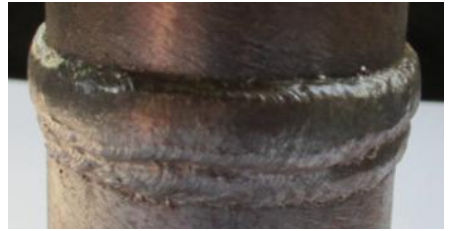

(a)

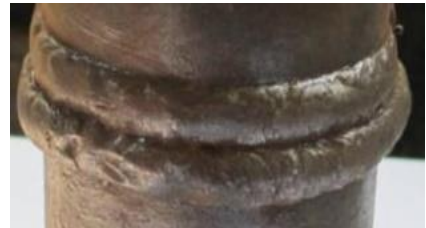

(b)

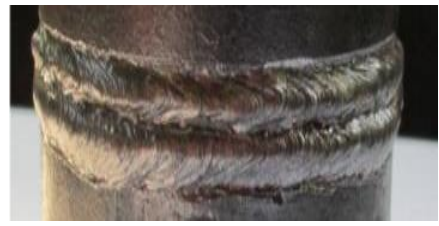

(c)

Gambar 3. Hasil Pengelasan Spesimen (a) $1 \mathrm{rpm}$, (b) 1,5 rpm (c) 2 rpm

Pada gambar 3 dapat terlihat semakin tinggi kecepatan putar maka rigi-rigi las yang dihasilkan akan semakin terlihat kasar. 


\section{HASIL DAN PEMBAHASAN}

\subsection{Pengamatan Struktur Mikro}

Berikut ini adalah perbandingan struktur mikro pada 3 spesimen dengan variasi kecepatan pengelasan berbeda.

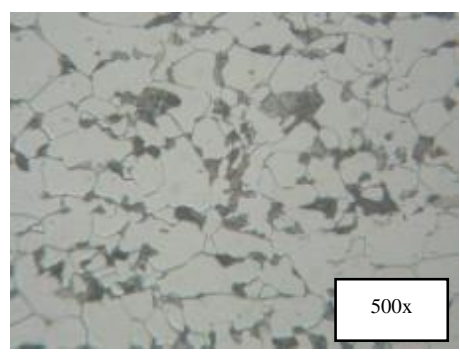

(a)

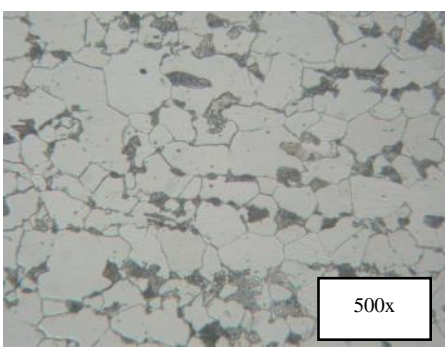

(b)

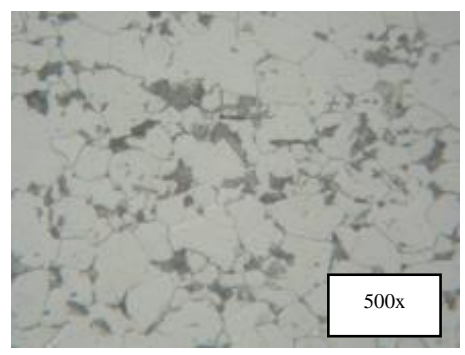

(c)

Gambar 4. Pengamatan Struktur Mikro Base Metal (a) $1 \mathrm{rpm}$, (b) 1,5 rpm (c) $2 \mathrm{rpm}$

Gambar 4 menunjukkan perbedaan bentuk struktur mikro pada spesimen 1, 1,5 dan $2 \mathrm{rpm}$. Struktru mikro yang terbentuk adalah perlit (hitam) dan ferrit (putih). Tidak terlalu signifikan perbedaan antara ketiga spesimen berdasarkan gambar di atas.

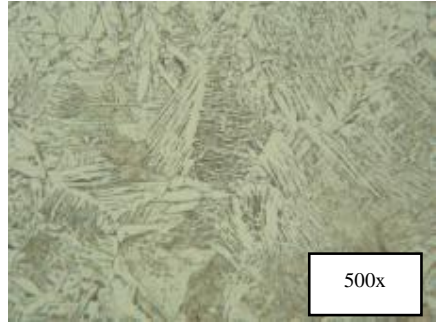

(a)

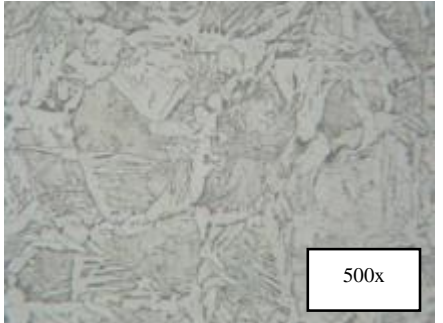

(b)

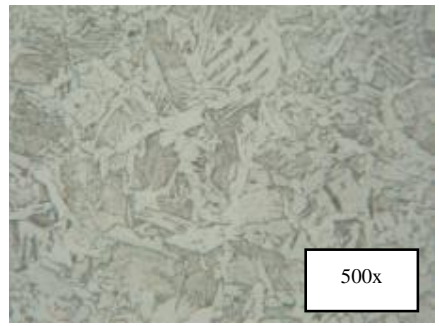

(c)

Gambar 5. Pengamatan Struktur Mikro HAZ (a) $1 \mathrm{rpm}$, (b) 1,5 rpm (c) $2 \mathrm{rpm}$

Gambar 5 menunjukkan perbedaan bentuk struktur mikro pada spesimen 1, 1,5 dan $2 \mathrm{rpm}$. Pada semua spesimen terlihat struktur yang terbentuk adalah widmanstatten dengan bainit dan serpih ferit.

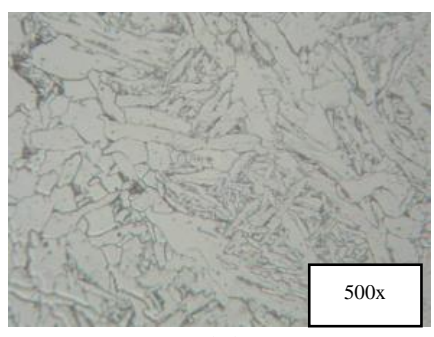

(a)

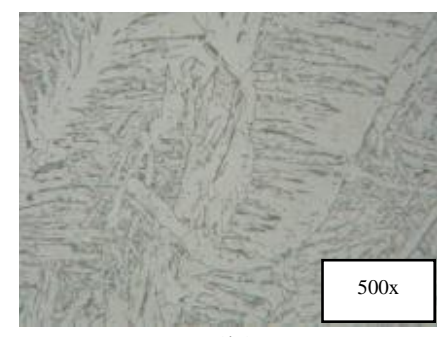

(b)

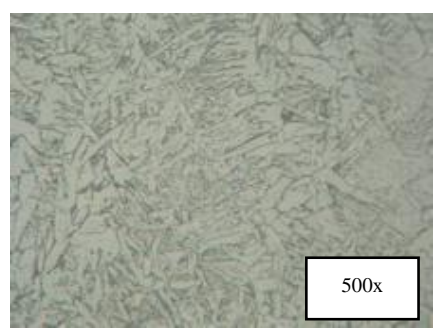

(c)

Gambar 6. Pengamatan Struktur Mikro Weld Metal (a) 1 rpm, (b) 1,5 rpm (c) 2 rpm

Gambar 6 menunjukkan perbedaan bentuk struktur mikro pada spesimen 1, 1,5 dan $2 \mathrm{rpm}$. Pada semua spesimen terlihat struktur yang terbentuk adalah bainit dan pro-eutektoid ferit. 


\subsection{Pengujian Kekerasan}

Uji kekerasan dilakukan kepada tiga spesimen dengan rata-rata 9 titik pada setiap spesimennya. Hal ini dapat terlihat pada grafik dibawah ini:

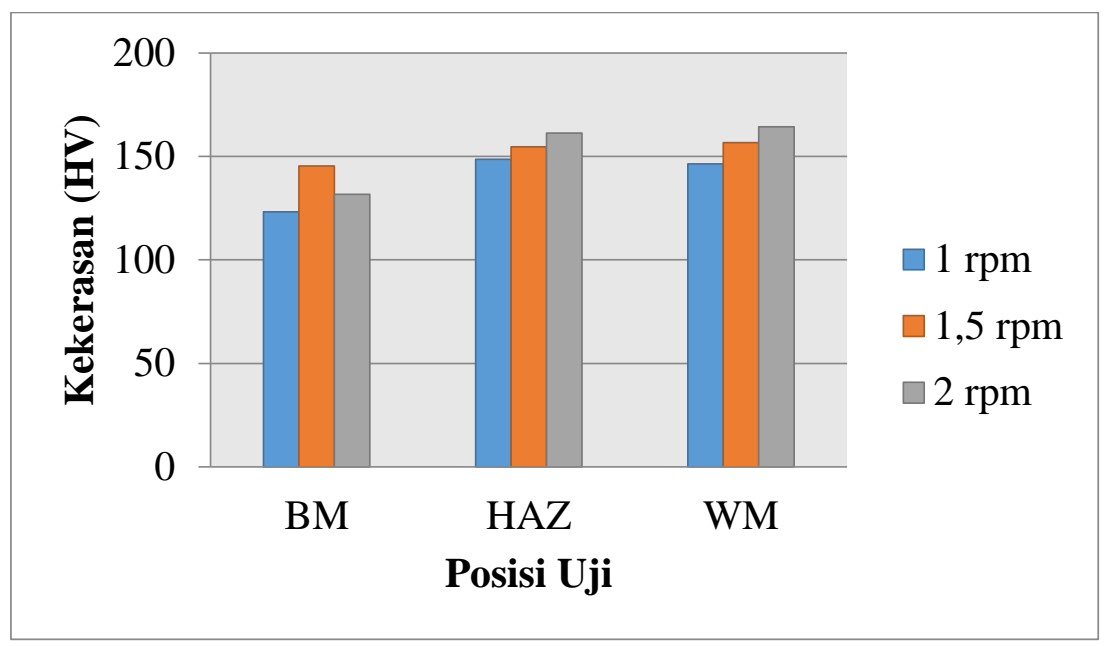

Gambar 7. Diagram Hasil Uji Kekerasan

Berdasarkan diagram di atas terlihat bahwa Base Metal pada spesimen 1,5 rpm lebih tinggi daripada Base Metal dari spesimen 1 dan 2 rpm. Daerah HAZ memiliki nilai kekerasan pada spesimen $2 \mathrm{rpm}$ lebih tinggi dari HAZ dari spesimen 1 dan 1,5 rpm. Daerah Weld Metal pada spesimen $2 \mathrm{rpm}$ memiliki nilai kekerasan lebih tinggi dari Weld Metal pada spesimen 1 dan $1,5 \mathrm{rpm}$

\section{KESIMPULAN}

Dari hasil pembahasan yang telah dilakukan maka dapat diambil kesimpulan sebagai berikut :

1) Semakin tinggi kecepatan putar maka rigi-rigi las akan semakin kasar.

2) Pengamatan struktur mikro menunjukkan semua sampel variasi kecepatan putar terbentuk struktur mikro yang sama.

3) Pada pengujian kekerasan, Weld Metal pada spesimen $2 \mathrm{rpm}$ adalah 164,33 $\mathrm{HV}$, lebih keras daripada Weld Metal pada spesimen 1 dan 1,5 rpm.

4) Pada daerah $H A Z$ dan spesimen 2 rpm juga lebih keras daripada $H A Z$ pada spesimen 1 dan 1,5 rpm dengan nilai kekerasan spesimen 2 rpm adalah 161,33 $H V$

\section{DAFTAR PUSTAKA}

Amstead, B. H., Phillip F. Ostwald, and Myron L. Begeman. "Teknologi mekanik jilid 1." Jakarta. Erlangga (1997).

Junus, Salahuddin. "Pengaruh Besar Aliran Gas terhadap Cacat Porositas dan Struktur Mikro Hasil Pengelasan MIG pada Paduan Aluminium 5083." Jurnal Rotor 4.1 (2011): 22-31.

Muku, I. Dewa Made Krishna, and Dewa Made Krishna. "Kekuatan Sambungan Las Aluminium Seri 1100 dengan Variasi Kuat Arus Listrik Pada Proses Las Metal Inert Gas (MIG)." Jurnal Ilmiah Teknik Mesin CakraM 3.1 (2009): 11-17. 
Prasetya, Alfian Wahyu, Rusiyanto Rusiyanto, and Pramono Pramono. "Pengaruh debit gas pelindung dan tegangan listrik terhadap tingkat kekerasan dan struktur mikro sambungan las GMAW pada baja karbon sedang EMS-45." Jurnal Kompetensi Teknik 8.2 (2017): 42-52.

Wiryosumarto, Harsono, and Toshi Okumura. "Teknik pengelasan logam." Erlangga, Jakarta (2000). 